\title{
Effect of Erythropoietin in patients with acute myocardial infarction: five-year results of the REVIVAL-3 trial
}

Birgit Steppich 1*0, Philip Groha', Tareq Ibrahim², Heribert Schunkert², Karl-Ludwig Laugwitz², Martin Hadamitzky', Adnan Kastrati ${ }^{1}$, Ika Ott $^{1}$ and for the Regeneration of Vital Myocardium in ST-Segment Elevation Myocardial Infarction by Erythropoietin (REVIVAL-3) Study Investigators

\begin{abstract}
Background: Erythropoietin (EPO) has been suggested to promote cardiac repair after Ml. However, the randomized, double-blind, placebo controlled REVIVAL-3 trial showed that short term high dose EPO in timely reperfused myocardium does not improve left ventricular ejection fraction after 6 months. Moreover, the study raised safety concerns due to a trend towards a higher incidence of adverse clinical events as well as a increase in neointima formation after treatment with EPO. The present study therefore aimed to assess the 5-year clinical outcomes.

Methods: After successful reperfusion 138 patients with STEMI were randomly assigned to receive epoetin beta $\left(3.33 \times 10^{4} \mathrm{U}, n=68\right)$ or placebo $(n=70)$ immediately, 24 and $48 \mathrm{~h}$ after percutaneous coronary intervention. The primary outcome of the present study- the combined incidence of MACE 5 years after randomization - occurred in $25 \%$ of the patients assigned to epoetin beta and $17 \%$ of the patients assigned to placebo (RR 1.5; 95\% Cl 0.8-3.5; $p=0$. 26). Target lesion revascularization was required in 15 patients (22.1\%) treated with epoetin-ß and 9 patients (12.9\%) treated with placebo $(p=0.15)$. Analysis of patients in the upper and lower quartile of baseline hemoglobin as an indirect estimate of endogenous erythropoietin levels revealed no significant impact of endogenous erythropoietin on efficiency of exogen administered epoetin- $\beta$ in terms of death and MACE.
\end{abstract}

Conclusion: These long-term follow-up data show that epoetin beta does not improve clinical outcomes of patients with acute myocardial infarction.

Trial registration: URL www.clinicaltrials.gov; Unique identifier NCT00390832; trial registration date October 19th 2006

Keywords: Erythropoietin, Acute myocardial infarction, REVIVAL-3 trial

\section{Background}

Despite continually improved treatment regimens the rate of death and heart failure is still substantially high after ST-elevation myocardial infarction (STEMI) [1-3].

The extent of myocardial necrosis is a main predictor of mortality and morbidity after STEMI. Cardiac necrosis is not only determined by the myocardial ischemia itself, but also driven by secondary damage upon reperfusion, the ischemia-reperfusion-injury. While the

\footnotetext{
* Correspondence: bigitsteppich@yahoo.de

'Deutsches Herzzentrum der Technischen Universität München, Lazarettstr.

36, 80636 Munich, Germany

Full list of author information is available at the end of the article
}

ischemia-induced necrosis can effectively be treated by timely myocardial reperfusion using percutaneous coronary intervention (PCI), reperfusion-induced necrosis is still barely preventable [4].

Erythropoietin (Epo), a hypoxia induced hormone, has been shown to play a cardioprotective role in various experimental models of myocardial ischemia and ischemia-reperfusion via pleiotropic actions [5]. Besides stimulation of haematopoesis, Epo induces mobilization of endothelial progenitor cells and promotes neovascularization and angiogenesis [6, 7]. It also exhibits antiapoptotic, anti-inflammatory and anti-oxidative properties 
in the heart [5], where cardiomyocytes and endothelial cells express functional Epo receptors $[8,9]$.

However, despite promising results of experimental and preclinical studies, we -like most other clinical trials- showed in the randomized, double-blind, placebo controlled REVIVAL-3 trial, that short-term, high dose epoetin beta in addition to successful PCI in STEMI does neither reduce infarct size nor improve left ventricular function at 6 months [10-12]. On the contrary we observed a trend towards a higher incidence of adverse clinical events 6 month after epoetin beta treatment as well as a significant increase in neointima formation in the erythropoietin group [13]. This raises safety concerns about the use of erythropoietin in patients with acute MI. By promoting neointima formation and imparing arterial healing, erythropoietin might affect clinical outcomes of STEMI patients over the longer term. Moreover legacy or memory effects can influence clinical prognosis even long after cessation of drug administration [14]. However clinical outcome data more than 12 month after erythropoietin therapy have never been reported in patients treated for myocardial infarction. Thus, the aim of the present trial was to assess the impact of high-dose, short term erythropoietin on longterm clinical outcomes in STEMI patients. For this purpose we extended the follow up of the REVIVAL-3 trial, which compared 3 daily IV doses of 33,000 I.U. of rhEpoetin beta administered immediately, 24 and $48 \mathrm{~h}$ after PCI in STEMI to placebo treatment, up to 5 years.

\section{Methods}

\section{Patients and protocol}

The detailed study design and main results from the REVIVAL-3 trial have been published previously [10]. In brief, the REVIVAL-3 study was a prospective, randomized, double-blind, placebo-controlled trial allocating patients with acute STEMI in a 1:1 ratio after successful primary PCI to medical treatment with either epoetin beta or placebo as a supplement to treatment according to guidelines.

To be included patients had to present with a first STEMI within $24 \mathrm{~h}$ of symptom onset and had to have an angiographic left ventricular ejection fraction (LVEF) of less than $50 \%$ by visual estimation in the angiogramm. The study drug was given immediately after successful PCI in the catheterization laboratory as well as 24 and $48 \mathrm{~h}$ after randomization. Each time, patients received either $3.33 \times$ $10^{4} \mathrm{IU}$ of recombinant human epoetin- $\beta$ (NeoRecormon; F. Hoffmann-La Roche, Basel, Switzerland) or a matching placebo intravenously for $30 \mathrm{~min}$. The periprocedural antithrombotic therapy consisted of $600 \mathrm{mg}$ of clopidogrel orally, $500 \mathrm{mg}$ aspirin, and unfractionated heparin with or without abciximab intravenously. Heparin was given as a bolus of $140 \mathrm{IU}$ or $70 \mathrm{IU}$ in case of additional abciximab
( $0.25 \mathrm{mg} / \mathrm{kg}$ body weight bolus, followed by an infusion of $0.125 \mu \mathrm{g} / \mathrm{kg}$ per min for $12 \mathrm{~h}$ ). Postinterventional all patients recieved clopidogrel $75 \mathrm{mg}$ twice a day for 3 days followed by $75 \mathrm{mg} / \mathrm{d}$ for at least 6 months. Aspirin $100 \mathrm{mg}$ twice a day was recommended indefinitely.

The study protocol was approved by the institutional ethics committee and all patients gave written informed consent for participation in the study. The study has been registered in clinicaltrials.gov (NCT00390832).

One hundred thirty-eight patients were randomized, from January 2007 to November 2008 at the Deutsches Herzzentrum and 1st Medizinische Klinik rechts der Isar, to epoetin- $\beta(n=68)$ or placebo $(n=70)$ and finally included in the present extended follow up study.

\section{Clinical follow-up}

The pre-specified primary end point of the main REVIVAL-3 trial was LVEF 6 months after random assignment measured by MRI. Other end points included infarct size at 5 days and 6 months and clinical adverse events (death, recurrent myocardial infarction, stroke, and infarct-related artery revascularization) at 30 days and 6 months.

Epoetin did not improve LVEF or reduce infarct size at 6 months follow up. On the contrary, there was a trend toward a higher adverse event rate with erythropoietin at 6 months.

The primary outcome of interest for the current analysis was the combined incidence of major adverse cardiac events (MACE), including death, recurrent MI, stroke, coronary bypass surgery (ACVB) and target vessel revascularistion, 5 years after randomization. The incidence of the individual components of the primary end point was also assessed. Information on vital status, recurrent MI, target vessel revascularization and stroke was collected by annual telephone interviews and from hospital records. In case the patients reported cardiac symptoms during the interview, complete clinical, electrocardiogram, and laboratory examination was performed in the outpatient clinic or by the referring physician. Reinfarction was defined as the onset of recurrent symptoms of ischemia combined with new STsegment elevations and/or a second increase of serum CK or CK-MB to at least twice the upper limit of the normal range. Target vessel revascularization was defined as PCI or bypass grafting of the infarct-related coronary artery after primary PCI.

\section{Statistical analysis}

All data were analyzed on the basis of the intentionto-treat principle using data from all patients as randomized. Categorical data are presented as counts or proportions (\%). Continuous data are presented as mean \pm standard deviation. Differences between the 
groups were assessed using $\chi^{2}$ or Fisher exact test for categorical data and $t$ test for continuous data. The cumulative incidence of the composite end point during the 5-year-follow up was evaluated with the Kaplan Meier method. Survival free of adverse events was defined as the interval from randomization until the event of interest. Data for patients who did not have an event of interest were censored at the date of the last follow-up. The difference in the composite event rate between the 2 study groups was checked for significance by means of a Cox proportional hazards model, which also allowed the calculation of the respective hazard ratio with its $95 \%$ confidence interval. A 2-tailed probability value $<0.05$ was considered to indicate statistical significance. All analyses were performed using S-plus statistical package (S-PLUS, In- sightful Corp., Seattle, Washington).

\section{Results}

All 138 patients enrolled in the REVIVAL-3 trial were included in the present extend follow up study. All had received the randomly assigned medication: 68 epoetin$\beta$ and 70 placebo. One hundred thirty-four patients (97\%) completed the 5-years follow up, while 4 patients were lost to follow up. Detailed baseline characteristics of the patients have been published previously and were similarly distributed in the two treatment groups. Table 1 summarizes some key data of the study population.

The mean age of the patients was $59.1( \pm 13.0)$ years in the epoetin $-\beta$ group and $62.1( \pm 12.3)$ years in the control group, with a proportion of males of $82 \%$ versus $74 \%$. The median time from symptom onset to PCI was 252 (interquartile range 175-413) minutes in patients receiving epoetin- $\beta$ and 253 (interquartile range 165-457) minutes in patients in the control group. Baseline angiographic LVEF was $46 \%$ in both groups, indicating substantial myocardial infarction. The majority of patients presented with multi-vessel-disease $(62 \%$ versus $71 \%)$ and was treated with drug-eluting stents (93\% versus 95\%). Although epoetin- $ß$ induced an increase in circulating reticulocytes 5 days after random assignment $\left(11.3 \pm 3.8 \times 10^{4} / \mu \mathrm{l}\right.$ versus $10.9 \pm 4.18 \times 10^{4} / \mu \mathrm{l} ; p=0.563$ to $34.2 \pm 9.58 \times 10^{4} / \mu \mathrm{l}$ versus $16.8 \pm 6.58 \times 10^{4} / \mu \mathrm{l} ; p=0.001$ ) and a rise in the maximal platelet count $\left(265 \pm 70 \times 10^{9} / 1\right.$ versus $\left.232 \pm 74 \times 10^{9} / \mathrm{l}, P=0.011\right)$, it was not associated with a rise in maximal hemoglobin levels $(14.8 \pm 1.6 \mathrm{mg} /$ $\mathrm{dl}$ versus $15 \pm 1.3 \mathrm{mg} / \mathrm{dl}, P=0.593$ ).

\section{Clinical outcome}

Table 2 summarizes the major clinical events registered after hospital discharge in both patient groups over the extended follow-up. A total of 14 patients (10\%) died during the 5 -years study period, $8(11.8 \%)$ in the epoetin- $\beta$ and 6 (8.6\%) in the control group ( $p=0.53$; Fig. 1a).
Table 1 Key characteristics of the study population

\begin{tabular}{|c|c|c|}
\hline & $\begin{array}{l}\text { Epoetin- } \beta \\
(n=68)\end{array}$ & $\begin{array}{l}\text { Placebo } \\
(n=70)\end{array}$ \\
\hline Age, mean y $( \pm S D)$ & $59.1(13.0)$ & $62.1(12.3)$ \\
\hline Women, n(\%) & $12(18)$ & $18(26)$ \\
\hline Body mass index, mean $( \pm S D)$ & $28(4)$ & $27(4)$ \\
\hline Diabetes, n(\%) & $11(16)$ & $10(14)$ \\
\hline Current smoker, n(\%) & $29(43)$ & $30(43)$ \\
\hline Multivessel disease, n(\%) & $42(62)$ & $50(71)$ \\
\hline Angiographic LVEF, mean \% ( \pm SD) & $46(8)$ & $46(8)$ \\
\hline \multicolumn{3}{|l|}{ Infarct related coronary artery, n(\%) } \\
\hline$\angle A D$ & $34(50)$ & $31(44)$ \\
\hline RCA & 19 (33.9) & $18(31.0)$ \\
\hline LCX & $7(12.5)$ & $12(20.7)$ \\
\hline LMCA & 0 & $1(1)$ \\
\hline \multicolumn{3}{|l|}{ Initial TIMI flow grade, n(\%) } \\
\hline 0 & $35(52)$ & $41(59)$ \\
\hline 1 & $11(16)$ & $11(14)$ \\
\hline 2 & $20(29)$ & $15(21)$ \\
\hline 3 & $2(3)$ & $4(6)$ \\
\hline \multicolumn{3}{|l|}{ Final TIMI flow grade, n(\%) } \\
\hline 1 & 0 & $1(1)$ \\
\hline 2 & $5(7)$ & $6(9)$ \\
\hline 3 & $63(93)$ & $63(90)$ \\
\hline \multicolumn{3}{|l|}{ Type of intervention, n(\%) } \\
\hline Bare metal stent & $3(4)$ & $3(4)$ \\
\hline Drug-eluting stent & $63(93)$ & $66(95)$ \\
\hline Balloon angioplasty & $2(3)$ & $1(1)$ \\
\hline Creatine kinase-MB max, U/L (range) & $201(121-450)$ & $213(124-312)$ \\
\hline Symtom onset to $\mathrm{PCl}$, min (range) & $252(175-413)$ & $253(165-457)$ \\
\hline Hemoglobin max, mean g/dl $( \pm S D)$ & $14.8(1.6)$ & $15(1.3)$ \\
\hline
\end{tabular}

Table 2 Summary of major clinical events registered after hospital discharge in both patient groups over the 5-year follow-up

\begin{tabular}{llll}
\hline & $\begin{array}{l}\text { EPO } \\
(n=68)\end{array}$ & $\begin{array}{l}\text { Placebo } \\
(n=70)\end{array}$ & \\
\hline Death; $\mathrm{n}(\%)$ & $8(11.8)$ & $6(8.6)$ & $p=0.53$ \\
Ml; $\mathrm{n}(\%)$ & $4(5.9)$ & $2(2.9)$ & $p=0.38$ \\
Death or Ml; $\mathrm{n}(\%)$ & $10(14.7)$ & $7(10.0)$ & $p=0.40$ \\
Stroke; $\mathrm{n}(\%)$ & $1(1.5)$ & $0(0)$ & $p=0.31$ \\
Death or Ml or Stroke; $\mathrm{n}(\%)$ & $10(14.7)$ & $7(10.0)$ & $p=0.40$ \\
Coronary bypass surgery; $\mathrm{n}(\%)$ & $1(1.5)$ & $0(0)$ & $p=0.31$ \\
Target lession revascularization; $\mathrm{n}(\%)$ & $15(22.1)$ & $9(12.9)$ & $p=0.15$ \\
MACE; $\mathrm{n}(\%)$ & $17(25.0)$ & $12(17.1)$ & $p=0.26$ \\
\hline
\end{tabular}



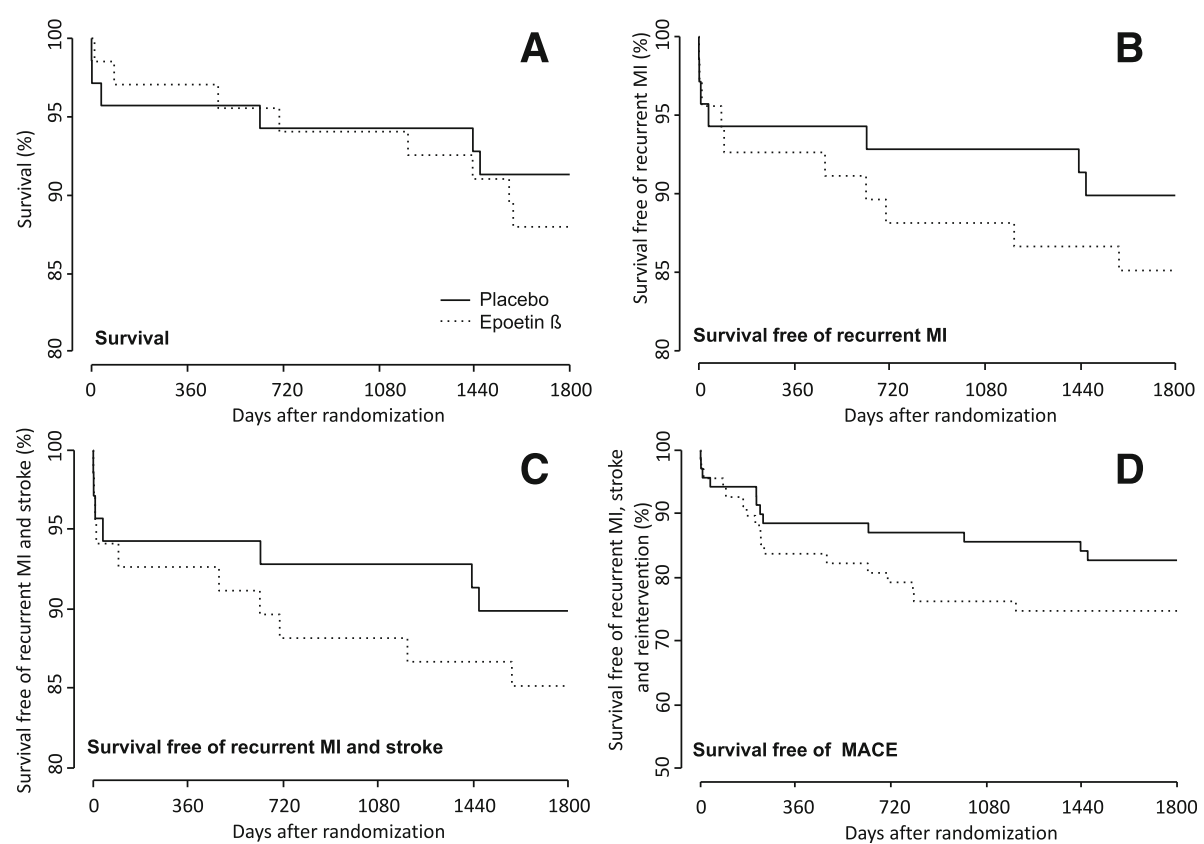

Fig. 1 Kaplan-Meier-Curves showing the cumulative event rates according to Epoetin beta therapy or Placebo. A Analysis of survival. B Analysis of survival free of recurrent myocardial infarction (MI). C Analysis of survival free of recurrent $\mathrm{MI}$ and stroke. D Analysis of survival free of MACE (recurrent Ml, stroke and reintervention)

While 2 epoetin- $\beta$ patients and 3 placebo patients had died during the initial 6 month follow up, 6 patients receiving epoetin- $\beta$ and 3 patients receiving placebo died between 6 month and 5 years. Individual causes of death are shown in Table 3.

Six patients (4.3\%) experienced MI, $2(2.9 \%)$ in the placebo and 4 (5.9\%) in the epoetin- $\beta$ group. Only 1 (1.5\%)

Table 3 Summary of patients who died during the 5 year follow up period

\begin{tabular}{lll}
\hline Patient \# & Group & Cause of death \\
\hline 1 & Placebo & cardiogenic shock \\
2 & Placebo & cardiogenic shock \\
3 & EPO & lung embolism \\
4 & Placebo & sudden cardiac death \\
5 & EPO & septic shock, stroke \\
6 & EPO & cancer \\
7 & Placebo & after orthopedic surgery \\
8 & EPO & sudden cardiac death \\
9 & EPO & unknown \\
10 & Placebo & cancer \\
11 & EPO & sudden cardiac death \\
12 & Placebo & unknown \\
13 & EPO & unknown \\
14 & EPO & unknown \\
\hline
\end{tabular}

Patient \# 1-5 died 1-186 days after randomization. Patient \# 7-14 died 1871860 days after randomization patient in the epoetin- $\beta$ group suffered a stroke $(p=$ 0.31 ). Coronary bypass surgery was also needed in 1 $(1.5 \%)$ epoetin- $\beta$ patient and none of the control patient $(p=0.31)$. Target lesion revascularization was required in 15 patients $(22.1 \%)$ treated with epoetin- $\beta$ and 9 patients $(12.9 \%)$ treated with placebo $(p=0.15)$.

Figure $1 \mathrm{~b}$ and $\mathrm{c}$ show the cumulative event rates of survival free of recurrent $\mathrm{MI}$ and survival free of recurrent $\mathrm{MI}$ and stroke.

The current primary outcome - the cumulative incidence of MACE 5 years after randomization - occurred in $25 \%(n=17)$ of the patients assigned to epoetin- $\beta$ and $17 \%(n=12)$ of the patients assigned to placebo (RR 1.5; 95\% CI 0.8-3.5; $p=0.26$; Fig. 1d).

To analyze if elevated endogenous erythropoietin levels might have interfered with effects of exogenous administered epoetin- $\beta$, we stratified the patients according to their hemoglobin level on admission. Since serum erythropoietin levels rise in an exponential manner with a decrease in hemoglobin levels [15], we analyzed clinical outcome of patients in the lower $(\mathrm{Hb}<$ $14,1 \mathrm{~g} / \mathrm{dl})$ and the upper $(\mathrm{Hb}>15,5 \mathrm{~g} / \mathrm{dl})$ quartile of hemoglobin concentration on admission separately. While the lower quartile consisted of 16 control patients and 23 erythropoietin-treated patients, the upper quartile comprised 34 patients, 19 treated by placebo and 15 by erythropoietin. During the 5 years follow up 1 death in the placebo group and 5 deaths in the erythropoietin group occurred in the lower Hb-quartile (Kaplan Meier 
estimates of death: $6.2 \%$ placebo, $21.7 \%$ epoetin- $\Omega ; p=$ 0.19 ), whereas 2 control and none of the erythropoietin patients experienced death in the upper $\mathrm{Hb}$-quartile (Kaplan Meier estimates of death: 10.5\% placebo, 0\% epoetin- $\Omega ; p=0.20$ ). The cumulative incidence of MACE 5 years after randomization occurred in $21.7 \%(n=5)$ of the patients assigned to epoetin- $\beta$ and $18.8 \%(n=3)$ of the patients assigned to placebo in the lower hemoglobin quartile $(p=0.82)$ and in $20 \%(n=3)$ in epoetin- $\beta$ and $21.1 \%(n=4)$ in placebo treated patients of the upper quartile $(p=0.94)$.

\section{Discussion}

This extended follow-up of the REVIVAL-3 trial revealed that high-dose, short-term epoetin- $\beta$ in addition to successful PCI does not improve clinical long-term outcomes of patients with acute myocardial infarction.

To the best of our knowledge, this is currently the study with the longest follow up analyzing erythropoietin effects in STEMI patients up to 5 years. All previous trials focused on the first 6 month and to date only the large HEBE III trial has provided one year follow up results [16].

While most other trials have to deal with the problem of a selective patient inclusion with small infarct sizes the REVIVAL-3 trial only randomized large infarctions affecting approximately $27-28 \%$ of the left ventricle with impaired LV-Function [10]. This ensures, that erythropoietin effects have been tested in an adequate ischemic condition.

Prognosis of patients with STEMI remains complicated by a substantial number of death, reinfarction and heart failure. According to real life registries like the REAL register the 3-year cumulative incidence of death is about $17.5 \%$ and MACE about $22.9 \%$ in STEMI patients treated by timely PCI with DES (drug eluting stents) [3]. Due to closely supervised and optimized therapy in the setting of RCT (randomzied controlled clinical trials) the present study has a somewhat lower however still substantial 5-year cumulative incidence of death (10\%) and MACE (21\%).

Since the extent of myocardial necrosis is a major determinant of adverse postinfarction-outcome, therapies able to further reduce infarct size are urgently needed. According to experimental in vivo and ex-vivo studies erythropoietin seemed to be such a promising candidate by its angiogenic, anti-inflammatory, anti-hypertrophic and anti-apoptotic properties [17]. It attenuated infarct expansion and detrimental cardiac remodeling, reduced infarct size and improved functional recovery in animal models of ischemic cardiac injury [5]. However our results are in line with the majority of clinical studies and recent meta-analyses, who all failed to demonstrate a benefit for shortterm erythropoetin therapy in PCI- treated STEMI patients in terms of both cardiac function and clinical prognosis [11, 18, 19]. A lot has been speculated about this erythropoetin paradox - why the overwhelming cardioprotective effects in animal studies could not be translated into humans.

Animal experiments were conducted in two major experimental models, MI induced by permanent ligation of a coronary artery or by temporary occlusion followed by reperfusion. In the model of permanent occlusion animals were mostly treated by a single intraperitoneal dose of $3000-5000 \mathrm{IU} / \mathrm{kg}$ of body weight erythropoietin immediately after ligation or even before $[20,21]$. The best results were achieved when EPO was applied at the time of occlusion. Dose regimes in cardiac ischemia-reperfusion worked also primarily with high doses of 2500-5000 IU/ $\mathrm{kg}$ of body weight erythropoietin intraperitoneal or intravenous and most regimes included a dose given even before ischemia was induced. Most effective results were observed when treatment was applied no later than at the time of reperfusion, i.e., 30-90 min from coronary occlusion. In contrast the majority of clinical trials did not adjust the erythropoietin dose to the individual body weight, in fact doses ranged between 30000-60000 IU, which corresponds to $430-860 \mathrm{IU} / \mathrm{kg}$ for a $70 \mathrm{~kg}$ patient. Drug application was carried out between 6 to $48 \mathrm{~h}$ in average after symptom onset $[20,21]$.

Therefore as a possible explanation of the erythropoietin-paradox, mostly dosing and timing of erythropoietin-administration has been supposed to be inappropriate, especially since experimental studies have shown the existence of a dose-dependent therapeutic window of time subsequent to reperfusion [22]. Beyond this window the erythropoietin induced tissue-protection is reduced or even abolished.

For example, Moon et al. showed in a rat model of permanent coronary ligation, that erythropoietin mediated cardioprotection with $3000 \mathrm{IU} / \mathrm{kg}$ of body weight was still effective when administration was delayed up to $12 \mathrm{~h}$ after ischemic injury, but not if the treatment was delayed for $24 \mathrm{~h}$. With the lowest effective dose of $150 \mathrm{IU} / \mathrm{kg}$ of body weight beneficial effects were only observed when administered within $4 \mathrm{~h}$. This efficacy was already lost when the administration was delayed by $8 \mathrm{~h}$ [23].

Our trial is among the studies with the highest erythropoietin doses used, nevertheless still substantial lower than those used in animal studies, and increasing the dosage further would mean increasing the risk of thromboembolic events due to elevated heamatocrit levels [24]. On the other hand, we administered erythropoietin as soon as possible in our clinical setting, namely immediately with PCI. However the average time from symptom-onset to PCI was about $250 \mathrm{~min}$, exceeding the above mentioned critical time window limit of $4 \mathrm{~h}$ 
according to animal studies. Therefore, application of erythropoietin even in advance to PCI or intracoronary might be necessary to be protective and beneficial. The recently published Intra-Co-EpoMI trial however failed to demonstrate reduction of infarct size 3 months after randomized intracoronary administration of a single dose darbepoetin-alpha in STEMI patients [25]. Another novel, promising approach to increase erythropoietin doses and thereby prolong the therapeutic window without increasing the thromboembolic risk, might be the new erythropoietin derivates, which display no haematopoietic effects by preserved cardioprotection [26].

A central issue of the erythropoietin paradox however might lay in the difference between animal models and the real human world [27].

Erythropoietin mediated cardioprotective effects seem to differ across species. While cardioprotection has been clearly shown in ischemia-reperfusion models in small rodents including mouse and rabbit, experiments in larger animals such as sheep and pig were either negative or controversial [20, 21]. As mentioned above experimental studies testing erythropoietin effects in myocardial infarction mostly used healthy animals and mimicked myocardial ischemia by mechanical injury of the coronary artery. This basically contrasts the process of MI in humans. Although MI is an acute phenomenon it develops on the basis of atherosclerosis and is the final stage of this chronic complex disease. STEMI patients often experience periods of stable or unstable angina with hypoxia and/or hypoperfusion and suffer from different degrees of congestive heart failure. Therefore, they can exhibit pathologically elevated erythropoietin levels leading to erythropoietin resistance. It has been shown, that raised endogenous plasma erythropoietin concentrations in patients with congestive heart failure are associated with increased cardiovascular mortality [28]. This might also explain why we not only found no improvement of clinical outcome, but observed a trend towards an increase in MACE following epoetin beta - a trend we had already seen in the original REVIVAL 3 trial after 6 months of follow up. While $62-71 \%$ of our study patients presented with multivessel disease, in the current metaanalysis on patient level by Fokkema et al. only $36 \%$ of the patients included had multivessel disease indicating a less advanced, pronounced and preceded disease process [11]. Therefore, Epoetin- $\beta$ therapy might have encountered different endogenous erythropoietin levels, resulting in the observed adverse outcome.

Separate analysis of patients in the upper and lower quartile of baseline hemoglobin as an indirect estimate of endogenous erythropoietin levels revealed no significant impact of endogenous erythropoietin on efficiency of exogen administered epoetin- $\beta$ in terms of death and MACE - although a definitive conclusion can't be drawn, since the event numbers are too small. However endogenous erythropoietin might not be the only confounder present. Hypertension, diabetes, aging and concomitant medication can also interfere with erythropoietin-mediated cardioprotection in clinical settings. Morphine, statins, ACE-inhibitors, angiotensin II receptor blockers, antidiabetics and clopidogrel are known to influence conditioning-induced cardioprotection and might overdrive or damp beneficial erythropoietin effects [20].

The REVEAL study by Najjar et al. on 222 patients with STEMI showed a higher incidence of death, MI, stroke and stent thrombosis upon erythropoietin use during the first 12 weeks. A subgroup analysis even revealed increased infarct size among erythropoietin patients 70 years or older [29]. Although other studies on erythropoietin in STEMI patients did not find an increased risk of adverse events over the short term, side effects of erythropoietin therapy are evident for other indications like heart failure, renal disease, anemia or cancer $[30,31]$. In patients with systolic heart failure and anemia darbopoetin was accompanied by a significant increase in thrombembolic events and septic shock [32]. Side effects have been linked to erythropoietin induced increases in haematocrit, blood viscosity, blood pressure, vasoconstriction or platelet function [33]. In the present study the non-significant rise in adverse clinical events after 5 years was mainly driven by more frequent target vessel revascularization in response to epoetin beta. Corresponding quantitative coronary angiography after six months revealed an increase in segment diameter stenosis in the epoetin beta group ( $32 \pm 19 \%$ vs. $26 \pm 14 \%$, p $=0.046$ ). Despite a subtle induction of circulating progenitor cells by erythropoietin, the observed increase in neointima formation was not associated with progenitor cell mobilization [13]. In a rat carotid artery model of vascular injury erythropoietin induced excessive neointima formation [34]. Experimental studies in vascular lesions in mice are less clear: one study reported inhibition of neointima hyperplasia due to enhanced reendothelialisation by mobilized endothelial progenitor cells and resident endothelial cells [35], while another study described increased neointima formation upon erythropoietin treatment due to enhanced smooth muscle cell proliferation by paracrine effects of the endothelium [36]. A clinical trial, designed to analyze the effect of erythropoietin on restenosis, failed to demonstrate, that short-term 'low-dose' epoetin beta prevented neointimal hyperplasia in PCI-treated AMI patients [37].

Our study is limited by the fact, that the REVIVAL-3 trial was powered to detect differences in left ventricular ejection fraction and was not designed to evaluate effects on long-term clinical outcomes. Although the relatively 
low number of patients enrolled precludes definitive conclusions about clinical prognosis, we believe that the herein presented data can provide nevertheless valuable insights, since $97 \%$ of the study patients completed the 5-year clinical follow-up and it's to date the only study providing clinical outcome data more than 12 month after epoetin treatment in AMI.

\section{Conclusion}

These 5 years follow-up data show that short-term use of 3 IV doses epoetin beta in PCI-treated STEMI patients does not improve clinical long-term prognosis. Our results further support the erythropoietin paradox and advise caution regarding the application of erythropoetin in patients with STEMI.

\section{Abbreviations \\ REVIVAL: Regenerate Vital Myocardium by Vigorous Activation of Bone Marrow Stem cells; STEMI: ST-elevation myocardial infarction; MI: Myocardial infarction; PCl: Percutaneous coronary intervention; EPO: Erythropoietin; LVEF: Left ventricular ejection fraction; MACE: Major adverse cardiac events; MRI: Magnetic resonance imaging; ACVB: Coronary bypass surgery}

\section{Acknowledgments}

We appreciate the invaluable contribution of the medical and technical staffs operating in the coronary care units, nuclear medicine, and catheterization laboratories of the participating institutions.

\section{Funding}

There is no external or commercial funding to be reported. The REVIVAL-3 trial was solely sponsored by the German Heart Center.

\section{Availability of data and materials}

Because oft the large volume of data, the data for the patients included in the REVIVAL-3 trial are stored at the ISAResearch Center, German Heart Center Munich, Lazarettstr. 36, 80636 Munich, Germany. (http://www.dhm.mhn.de/de/kliniken_und_institute/klinik_fuer_herzund_kreislauf/wissenschaftliche_arbeitsgrupp/isar_research_center_interven.cfm)

\section{Authors'contributions}

Design, conception and conduction of the study: IO, AK; coordination of the study and data collection: $\mathrm{PG}, \mathrm{TI}, \mathrm{HS}, \mathrm{K}-\mathrm{LL}, \mathrm{MH}_{\text {, }} \mathrm{AK}, \mathrm{IO}, \mathrm{BS}$; statistical analysis and data interpretation: $1 \mathrm{O}, \mathrm{AK}, \mathrm{MH}, \mathrm{BS}$; manuscript writing: $\mathrm{BS}$. All authors read and approved the final manuscript.

\section{Competing interest}

The authors declare that they have no competing interests.

\section{Consent for publication}

Not applicable.

\section{Ethics approval and consent to participate}

The REVIVAL-3 trial was conducted in accordance with the Declaration of Helsinki. The study protocol was approved by the institutional ethics committee responsible for both participating centers (Ethikkommission der Fakultät für Medizin der Technischen Universität München, Grillparzerstraße 16, 81675 Munich, Germany; ethikkommission@mri.tum.de). Written informed consent was obtained from each patient. The study has been registered in clinicaltrials.gov (NCT00390832)

\section{Author details}

'Deutsches Herzzentrum der Technischen Universität München, Lazarettstr. 36, 80636 Munich, Germany. ${ }^{2}$ Medizinische Klinik Klinikum rechts der Isar der Technischen Universität München, Ismaningerstr. 22, 81675 Munich, Germany.
Received: 17 April 2016 Accepted: 29 December 2016

Published online: 21 January 2017

\section{References}

1. Campo G, Guastaroba P, Marzocchi A, Santarelli A, Varani E, Vignali L, Sangiorgio P, Tondi S, Serenelli C, De Palma R, Saia F. Impact of COPD on long-term outcome after ST-segment elevation myocardial infarction receiving primary percutaneous coronary intervention. Chest. 2013;144(3): 750-7.

2. Campo G, Saia F, Guastaroba P, Marchesini J, Varani E, Manari A, Ottani F, Tondi S, De Palma R, Marzocchi A. Prognostic impact of hospital readmissions after primary percutaneous coronary intervention. Arch Intern Med. 2011:171(21):1948-9.

3. Campo G, Saia F, Percoco G, Manari A, Santarelli A, Vignali L, Varani E, Benassi A, Sangiorgio P, Tarantino F, Magnavacchi P, De Palma R, Guastaroba P, Marzocchi A. Long-term outcome after drug eluting stenting in patients with ST-segment elevation myocardial infarction: data from the REAL registry. Int J Cardiol. 2010;140(2):154-60.

4. Dominguez-Rodriguez A, Abreu-Gonzalez P, Reiter RJ. Cardioprotection and pharmacological therapies in acute myocardial infarction: Challenges in the current era. World J Cardiol. 2014;6(3):100-6

5. Sanchis-Gomar F, Garcia-Gimenez JL, Pareja-Galeano H, Romagnoli M, PerezQuilis C, Lippi G. Erythropoietin and the heart: physiological effects and the therapeutic perspective. Int J Cardiol. 2014;171(2):16-125.

6. Heeschen C, Aicher A, Lehmann R, Fichtlscherer S, Vasa M, Urbich C, Mildner-Rihm C, Martin H, Zeiher AM, Dimmeler S. Erythropoietin is a potent physiologic stimulus for endothelial progenitor cell mobilization. Blood. 2003;102(4):1340-6.

7. van der Meer P, Lipsic E, Henning RH, Boddeus K, van der Velden J, Voors AA, van Veldhuisen DJ, van Gilst WH, Schoemaker RG. Erythropoietin induces neovascularization and improves cardiac function in rats with heart failure after myocardial infarction. J Am Coll Cardiol. 2005;46(1):125-33.

8. Anagnostou A, Liu Z, Steiner M, Chin K, Lee ES, Kessimian N, Noguchi CT. Erythropoietin receptor mRNA expression in human endothelial cells. Proc Natl Acad Sci U S A. 1994:91(9):3974-8.

9. Wright GL, Hanlon P, Amin K, Steenbergen C, Murphy E, Arcasoy MO. Erythropoietin receptor expression in adult rat cardiomyocytes is associated with an acute cardioprotective effect for recombinant erythropoietin during ischemia-reperfusion injury. FASEB J. 2004;18(9):1031-3.

10. Ott I, Schulz S, Mehilli J, Fichtner S, Hadamitzky M, Hoppe K, Ibrahim T, Martinoff S, Massberg S, Laugwitz KL, Dirschinger J, Schwaiger M, Kastrati A Schömig A, REVIVAL-3 Study Investigators. Erythropoietin in patients with acute ST-segment elevation myocardial infarction undergoing primary percutaneous coronary intervention: a randomized, double-blind trial. Circ Cardiovasc Interv. 2010;3(5):408-13

11. Fokkema M, van der Meer LP, Rao SV, Belonje AM, Ferrario M, Hillege HL, Katz SD, Lipšic E, Ludman AJ, Ott I, Prunier F, Choi DJ, Toba K, van Veldhuisen DJ, Voors AA. Safety and clinical outcome of erythropoiesisstimulating agents in patients with ST-elevation myocardial infarction: A meta-analysis of individual patient data. Am Heart J. 2014;168(3):354-62. e352.

12. Ali-Hassan-Sayegh S, Mirhosseini SJ, Tahernejad M, Mahdavi P, Haddad F, Shahidzadeh A, Lotfaliani MR, Sedaghat-Hamedani F, Kayvanpour E, Weymann A, Sabashnikov A, Popov AF. Administration of erythropoietin in patients with myocardial infarction: does it make sense? An updated and comprehensive meta-analysis and systematic review. Cardiovasc Revasc Med. 2015:16(3):179-89.

13. Stein A, Mohr F, Laux M, Thieme S, Lorenz B, Cetindis M, Hackl J, Groha P, Demetz G, Schulz S, Mehilli J, Schömig A, Kastrati A, Ott I. Erythropoietininduced progenitor cell mobilisation in patients with acute ST-segmentelevation myocardial infarction and restenosis. Thromb Haemost. 2012; 107(4):769-74

14. Chalmers J, Cooper ME. UKPDS and the legacy effect. N Engl J Med. 2008; 359(15):1618-20

15. Mastromarino V, Volpe M, Musumeci MB, Autore C, Conti E. Erythropoietin and the heart: facts and perspectives. Clin Sci. 2011;120(2):51-63.

16. Fokkema ML, Kleijn L, Van der Meer P, Belonje AM, Achterhof SK, Hillege HL, Van 't Hof A, Jukema JW, Peels HO, Henriques JP, ten Berg JM, Vos J, van Gilst WH, van Veldhuisen DJ, Voors AA. Long term effects of epoetin alfa in patients with ST- elevation myocardial infarction. Cardiovasc Drugs Ther. 2013;27(5):433-9. 
17. Wen Y, Zhang XJ, Ma YX, Xu XJ, Hong LF, Lu ZH. Erythropoietin attenuates hypertrophy of neonatal rat cardiac myocytes induced by angiotensin-II in vitro. Scand J Clin Lab Invest. 2009;69(4):518-25.

18. Gao D, Ning N, Niu X, Dang Y, Dong X, Wei J, Zhu C. Erythropoietin treatment in patients with acute myocardial infarction: a meta-analysis of randomized controlled trials. Am Heart J. 2012;164(5):715-27. e711.

19. Wen $Y, X u$ J, Ma X, Gao Q. High-dose erythropoietin in acute ST-segment elevation myocardial infarction: a meta-analysis of randomized controlled trials. Am J Cardiovasc Drugs. 2013;13(6):435-42.

20. Roubille F, Prunier F, Barrère-Lemaire $S$, Leclercq F, Piot $C$, Kritikou EA, Rhéaume $E$, Busseuil $D$, Tardif JC. What is the role of erythropoietin in acute myocardial infarct? Bridging the gap between experimental models and clinical trials. Cardiovasc Drugs Ther. 2013;27(4):315-31.

21. Talan MI, Latini R. Myocardial infarction: cardioprotection by erythropoietin. Methods Mol Biol. 2013:982:265-302.

22. Talan MI, Ahmet I, Lakatta EG. Did clinical trials in which erythropoietin failed to reduce acute myocardial infarct size miss a narrow therapeutic window? PLoS One. 2012;7(4):e34819.

23. Moon C, Krawczyk M, Lakatta EG, Talan MI. Therapeutic effectiveness of a single vs multiple doses of erythropoietin after experimental myocardial infarction in rats. Cardiovasc Drugs Ther. 2006;20(4):245-51.

24. Greenberg G, Assali A, Vaknin-Assa H, Brosh D, Teplitsky I, Fuchs S, Battler A, Kornowski R, Lev El. Hematocrit level as a marker of outcome in ST-segment elevation myocardial infarction. Am J Cardiol. 2010;105(4):435-40.

25. Roubille F, Micheau A, Combes S, Thibaut S, Souteyrand G, Cayla G, Bonello L, Lesavre N, Sportouch-Dukhan C, Klein F, Berboucha S, Cade S, Cung TT, Raczka F, Macia JC, Gervasoni R, Cransac F, Leclercq F, Barrère-Lemaire S, Paganelli F, Mottref P, Vernhet Kovacsik H, Ovize M, Piot C. Intracoronary administration of darbepoetin-alpha at onset of reperfusion in acute myocardial infarction: results of the randomized Intra-Co-EpoMl trial. Arch Cardiovasc Dis. 2013;106(3):135-45.

26. Sanchis-Gomar F, Perez-Quilis C, Lippi G. Erythropoietin receptor (EpoR) agonism is used to treat a wide range of disease. Mol Med. 2013;19:62-4.

27. Seifirad S. An emerging need for developing new models for myocardial infarction as a chronic complex disease: lessons learnt from animal vs. human studies on cardioprotective effects of Erythropoietin in reperfused myocardium. Front Physiol. 2014;5:44.

28. van der Meer $P$, Voors AA, Lipsic E, Smilde TD, van Gilst WH, van Veldhuisen DJ. Prognostic value of plasma erythropoietin on mortality in patients with chronic heart failure. J Am Coll Cardiol. 2004:44(1):63-7.

29. Najjar SS, Rao SV, Melloni C, Raman SV, Povsic TJ, Melton L, Barsness GW Prather K, Heitner JF, Kilaru R, Gruberg L, Hasselblad V, Greenbaum AB, Patel M, Kim RJ, Talan M, Ferrucci L, Longo DL, Lakatta EG, Harrington RA, REVEAL Investigators. Intravenous erythropoietin in patients with ST-segment elevation myocardial infarction: REVEAL: a randomized controlled trial. JAMA. 2011;305(18):1863-72.

30. Pfeffer MA, Burdmann EA, Chen CY, Cooper ME, de Zeeuw D, Eckardt KU, Feyzi JM, Ivanovich P, Kewalramani R, Levey AS, Lewis EF, McGill JB, McMurray JJ, Parfrey P, Parving HH, Remuzzi G, Singh AK, Solomon SD, Toto $\mathrm{R}$, TREAT Investigators. A trial of darbepoetin alfa in type 2 diabetes and chronic kidney disease. N Engl J Med. 2009;361(21):2019-32.

31. Macdougall IC, Roger SD, de Francisco A, Goldsmith DJ, Schellekens $H$, Ebbers H, Jelkmann W, London G, Casadevall N, Hörl WH, Kemeny DM, Pollock C. Antibody-mediated pure red cell aplasia in chronic kidney disease patients receiving erythropoiesis-stimulating agents: new insights. Kidney Int. 2012;81(8):727-32.

32. Swedberg K, Young JB, Anand IS, Cheng S, Desai AS, Diaz R, Maggioni AP, McMurray JJ, O'Connor C, Pfeffer MA, Solomon SD, Sun Y, Tendera M, VanVeldhuisen DJ, RED-HF Committees; RED-HF Investigators. Treatment of anemia with darbepoetin alfa in systolic heart failure. N Engl J Med. 2013; 368(13):1210-9.

33. Fishbane S, Besarab A. Mechanism of increased mortality risk with erythropoietin treatment to higher hemoglobin targets. Clin J Am Soc Nephrol. 2007:2(6):1274-82.

34. Reddy MK, Vasir JK, Hegde GV, Joshi SS, Labhasetwar V. Erythropoietin induces excessive neointima formation: a study in a rat carotid artery model of vascular injury. J Cardiovasc Pharmacol Ther. 2007;12(3):237-47.

35. Janmaat ML, Heerkens JL, de Bruin AM, Klous A, de Waard V, de Vries CJ. Erythropoietin accelerates smooth muscle cell-rich vascular lesion formation in mice through endothelial cell activation involving enhanced PDGF-BB release. Blood. 2010;115(7):1453-60.
36. Urao N, Okigaki M, Yamada H, Aadachi Y, Matsuno K, Matsui A, Matsunaga S, Tateishi K, Nomura T, Takahashi T, Tatsumi T, Matsubara H. Erythropoietinmobilized endothelial progenitors enhance reendothelialization via Aktendothelial nitric oxide synthase activation and prevent neointimal hyperplasia. Circ Res. 2006;98(11):1405-13.

37. Taniguchi N, Nakamura T, Sawada T, Matsubara K, Furukawa K, Hadase M, Nakahara Y, Nakamura T, Matsubara H. Erythropoietin prevention trial of coronary restenosis and cardiac remodeling after ST-elevated acute myocardial infarction (EPOC-AMI): a pilot, randomized, placebo-controlled study. Circ J. 2010;74(11):2365-71.

\section{Submit your next manuscript to BioMed Central and we will help you at every step:}

- We accept pre-submission inquiries

- Our selector tool helps you to find the most relevant journal

- We provide round the clock customer support

- Convenient online submission

- Thorough peer review

- Inclusion in PubMed and all major indexing services

- Maximum visibility for your research

Submit your manuscript at www.biomedcentral.com/submit
) Biomed Central 